\title{
Gliomas (astrocytomas) of the brain-stem with spinal intra- and extradural metastases: report of three cases
}

\author{
JOHN J. KEPES, CHARLES M. STRIEBINGER, CHARLES E. BRACKETT, \\ AND PULLA KISHORE
}

\begin{abstract}
From the Departments of Pathology and Oncology, Surgery (Neurosurgery) and Diagnostic Radiology (Neuroradiology) of the University of Kansas Medical Center, Kansas City, Kansas, U.S.A.
\end{abstract}

SYNOPSIS Astrocytomas of the pons and medulla oblongata ('brain-stem gliomas') while often invasive locally, do not as a rule seed and metastasize along the spinal meninges. Three cases are here reported (two adults, one child) in whom astrocytoma of the brain-stem metastasized along the spinal cord. The dura mater itself and the spinal epidural space were invaded in two cases. The child and one adult had a pontine astrocytoma, the other adult's tumour originated in the medulla oblongata. In the two cases that came to necropsy the tumour of the brain-stem was much better differentiated than the meningeal deposits. These three cases suggest that the possibility of spinal spread of brain-stem gliomas should be considered when dealing with diagnostic and therapeuti problems of such patients.

Dissemination of neuroectodermal tumours through cerebrospinal fluid pathways was first observed in medulloblastomas and this had been the only such tumour known to metastasize with any frequency until Russell and Cairns (1930) reported a case of spinal metastases from a fibrillary astrocytoma of the thalamus. This report was soon followed by similar observations by the same authors (Cairns and Russell, 1931) and others that have included gliomas of every type, originating from various parts of the brain (Polmeteer and Kernohan, 1947) and even the spinal cord itself (Roth and Elvidge, 1960). Curiously, astrocytomas of the pons and medulla oblongata, the so-called brain-stem gliomas, malignant and devastating as they may be in their area of origin, do not as a rule metastasize to the spinal subarachnoid space and the cauda equina.

We report three cases of brain-stem gliomas (astrocytomas), two from the pons and one from the medulla oblongata, that have seeded extensively through the spinal subarachnoid pathways with corresponding symptomatology. (Accepted 13 August 1975.)
Two of these have invaded through the spina dura mater to establish extradural tumouge deposits.

\section{CASE 1}

A $3 \frac{1}{2}$ year old female developed a right 6 th nerve weakness at the age of $1 \frac{1}{2}$ years. Three months before admission the child began to fall to the right, developed a right hemiparesis, right facial weakness, totally lost facial expression, and developed slurred speech with difficulty in chewing and swallowing. Examination showed impairment of left lateral gaze, ptosis on the left, bilateral facial paralysis, 12 th nerve weakness on the left, bilaterally absent gag reflex, severe ataxia, right hemiparesis, and choreoathetoid movements of the upper extremities. Lumbar spinal fluid protein was $1.74 \mathrm{~g} / 1$. Ventriculography showed marked enlargement of the pons and medulla diagnostic of an intra-axial brain-stem mass (Fig. 1). A ventriculoperitoneal shunt was done and 3000 rads of cobalt therapy given to the posterior fossa. Three months later on 16 July 1974 o she was readmitted because of hyperpyrexia and $N$ investigations revealed 792 white cells per $\mathrm{mm}^{3}$, N $1.67 \mathrm{mmol} / 1$ glucose, and $4.40 \mathrm{~g} / 1$ protein in the spinal fluid (CSF). No organisms could be cultured 


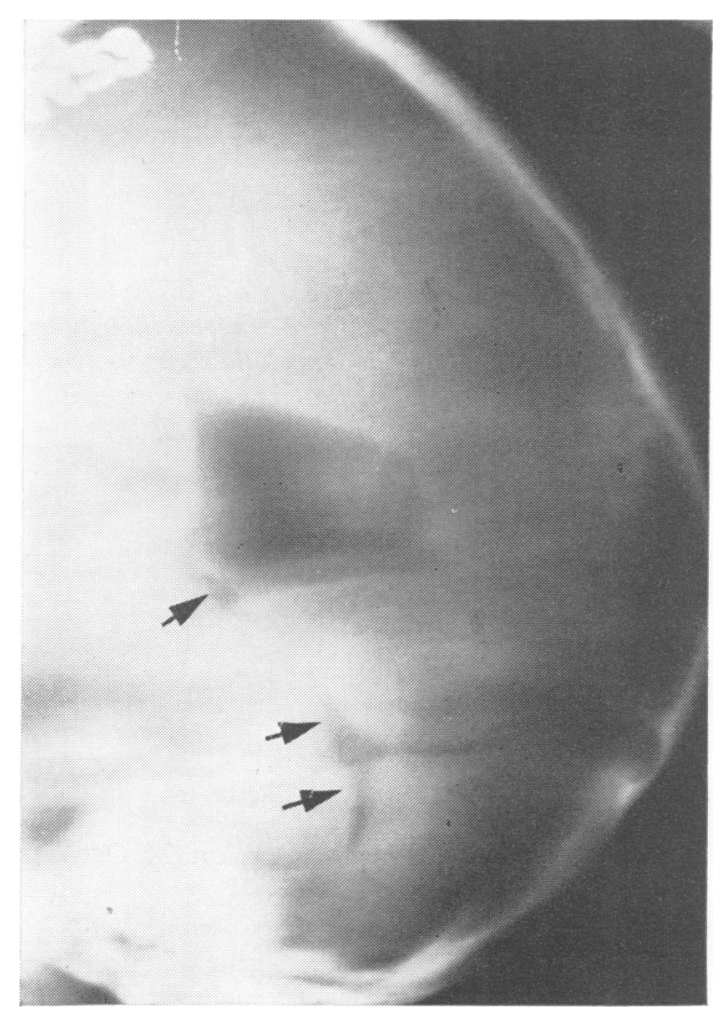

FIG. 1 Case 1. Ventriculogram: lateral radiograph of skull revealing posterior displacement of the aqueduct and fourth ventricle (arrows) consistent with an intra-axial brain-stem mass lesion.

from the CSF on repeated attempts and blood culture revealed Staph. epidermidis on one culture. Cytological examination of the cerebrospinal fluid showed cells consistent with malignancy suggesting poorly differentiated neoplasm, class IV. The patient responded to therapy with ampicillin and nafcillin and on discharge her cell count had dropped to 82 per $\mathrm{mm}^{3}$. She was readmitted on 7 September 1974 because of headache, irritability, and decreased stability while walking. Results of her neurological examination were unchanged. Terminal admission was on 24 October 1974 because of a one week history of leg pain, progressive paraparesis, and urinary incontinence. On examination the lower legs were hypotonic with marked weakness. CSF examination showed a cell count of 61 monocytes per $\mathrm{mm}^{3}$, glucose $2.33 \mathrm{mmol} / \mathrm{l}$, and protein $14.5 \mathrm{~g} / \mathrm{l}$. Cytology showed lymphocytes, polymorphonuclear leucocytes and occasional cells

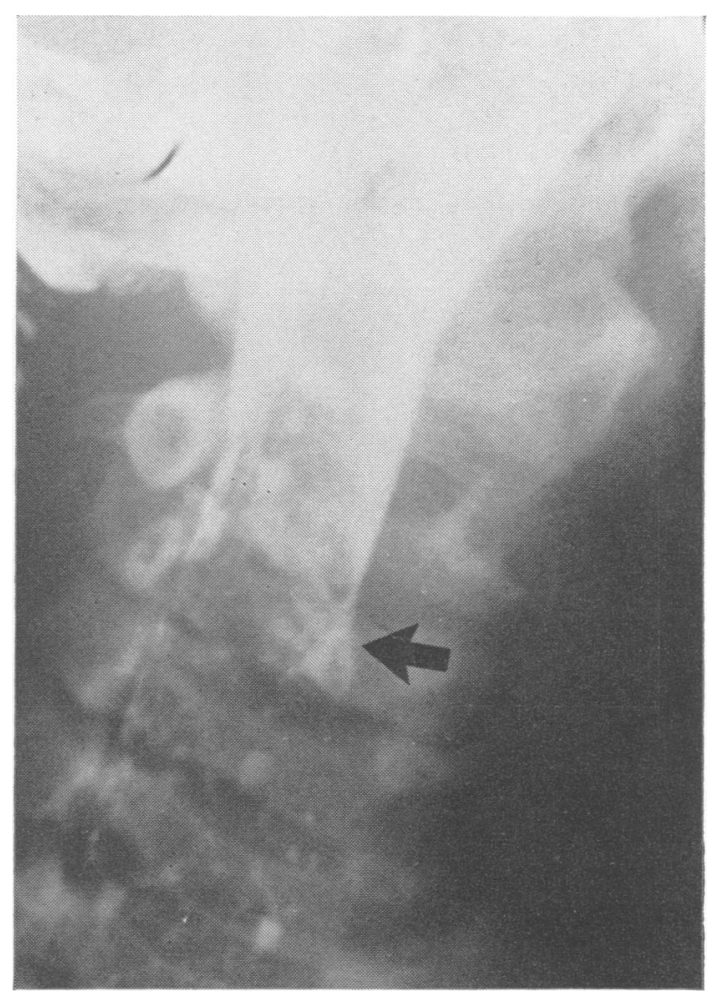

FIG. 2 Case 1. Iodophendylate (Pantopaque) myelogram by cisternal puncture in lateral upright position showing high-grade block at the level of C3 vertebra (arrow).

'suggestive of ependymal origin', class II. A myelogram was performed by cisternal puncture after unsuccessful attempts to instil iodophendylate into the lumbar subarachnoid space. The CSF was markedly xanthochromic and viscous. An almost total block was encountered at the level of C3 vertebra (Fig. 2). An exploratory laminectomy was carried out at $\mathbf{L}_{2}$ vertebra at the level of the paraparesis, on 25 September 1974, at which time a greyish-pink extradural tumour mass was found that also extended intradurally and surrounded the lower spinal cord and the roots of the cauda equina. Biopsy samples were taken from the extra- and intradural portions of that tumour.

The intradural tissue consisted of necrotic material only. The extradural tissue showed a malignant small cell tumour infiltrating epidural fat tissue. While many cells consisted only of a small dark nucleus surrounded by very scanty 


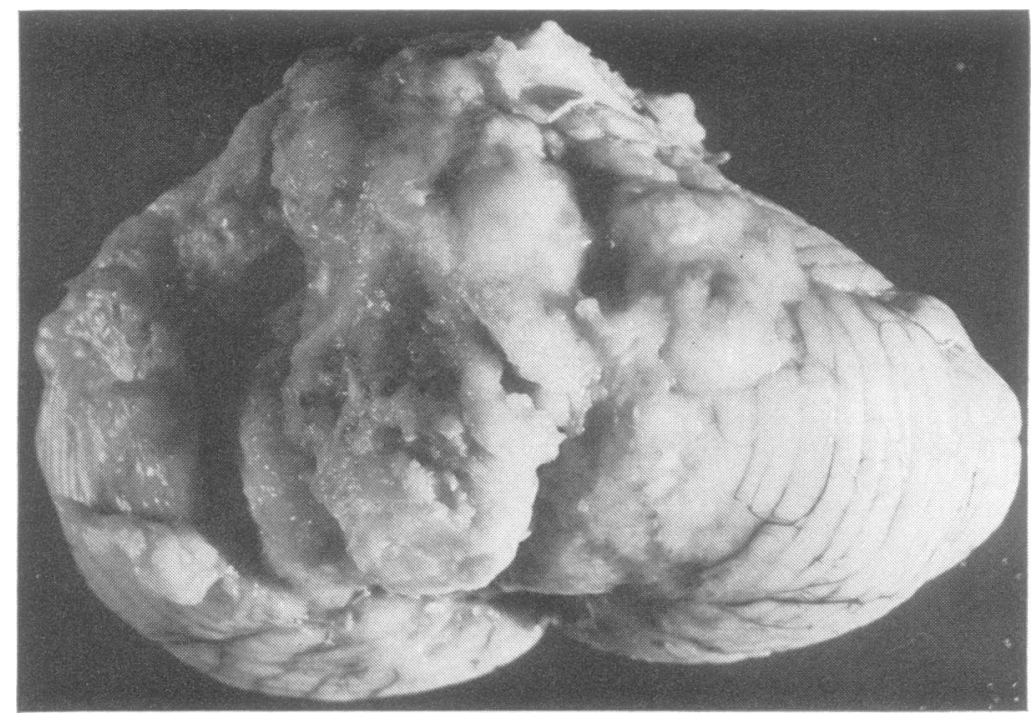

FIG. 3 Case 1. The lower surface of cerebellum, pons, and medulla is covered by white-grey subarachnoid tumour implants.

cytoplasm, a number of cells could be identified as neoplastic small astrocytes, and the diagnosis of malignant astrocytoma, metastatic to the spinal epidural space was rendered. In view of the clinical history, an astrocytoma of the brain-stem was assumed to be the primary source of this tumour.

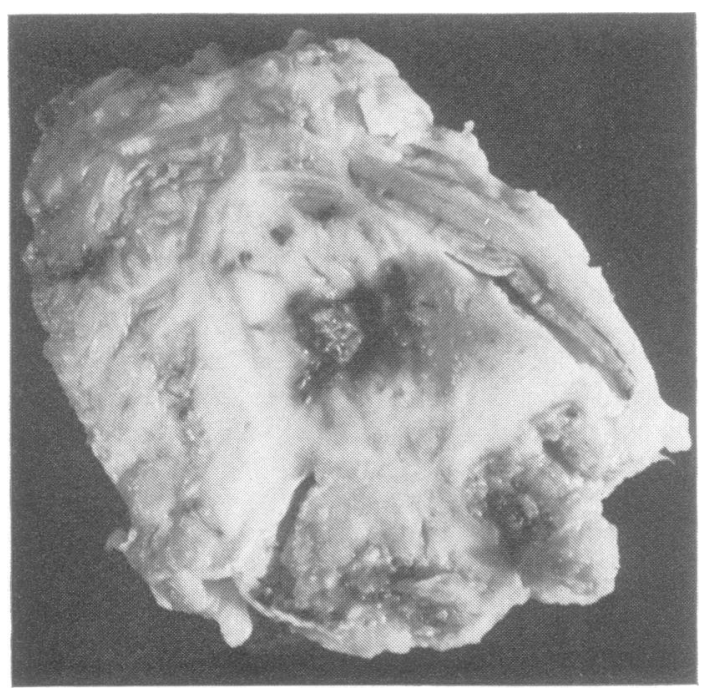

FIG. 4 Case 1. Cross-section of the pons shows destruction of the usual landmarks by infiltrating tumour.
The patient died one month later, on 24 Octobe? 1974.

PATHOLOGICAL FINDINGS The general necrops $B$ (Dr J. Reynard) showed marked cachexia. A shun connecting the right lateral ventricle of the braie $\overrightarrow{0}$ with the peritoneal cavity was in place; the abdominat oे end of the tube was free of obstruction. No gross abnormalities of the internal organs were recognized.

The brain weighed $1080 \mathrm{~g}$. The cerebral hemispheres were symmetrical and unremarkable on external examination but there was gross distortion in the configuration of the pons, medulla, and cerebellum, the basal surfaces of all three having been covered by nodular white tumour masses (Fig. 3). Coronal sectioning showed the origin of this tumour to be in the midpons, where the basis pontis was entirely and the tegmentum pontis partially replaced by white-grey, focally haemorrhagic tumour tissue that obliterated the normal anatomical landmarks of the pons. This tumour extended into the lumen of the fourth ventricle (Fig. 4). Rostrally, the tumour extended into the midbrain and both thalami, and tumour implants were seen within the lateral and third ventricles. Invasion of cerebellar white matter through the brachia pontis was also observed. The lower medulla and the spinal cord were totally encased in soft friable white tumour tissue (Fig. 5). In the cervical and upper thoracic regions the neoplastic growth was extramedullary but intradural; in the lower thoracic, lumbar, and sacral areas, however, 


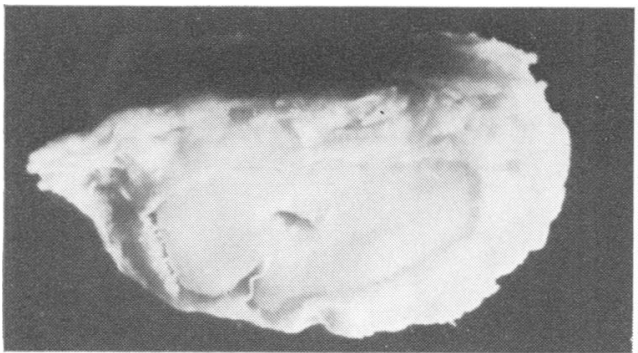

(a)

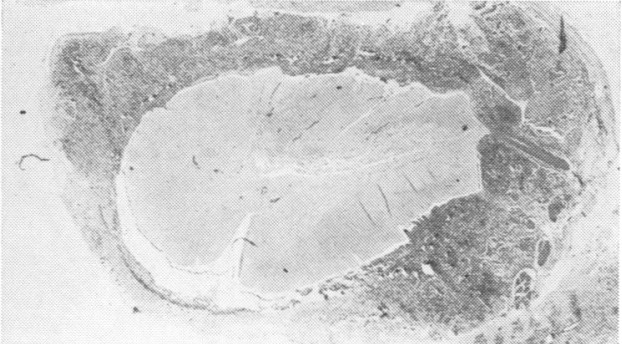

(b)

FIG. 5 (a) Case 1. Cross section of cervical spinal cord. Tumour masses occupy the subarachnoid space.

(b) Case 1. Same area, microscopic section, Nissl stain: the highly cellular subarachnoid tumour masses stain dark.

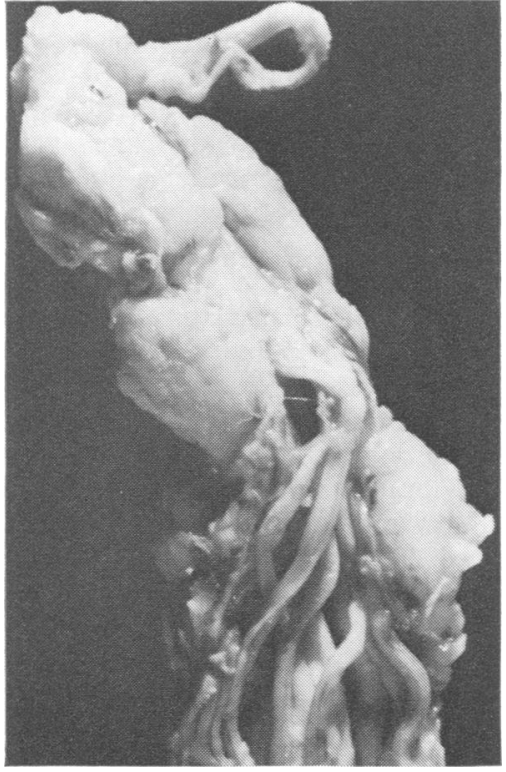

FIG. 6 Case 1. Tumour implants involve the conus medullaris and nerve roots of the cauda equina. the tumour penetrated the dura mater and neoplastic masses were seen both intra- and extradurally (Fig. 6).

The intrapontine portion of the tumour was consistent with a mostly moderately cellular pilocytic astrocytoma, featuring bipolar spindle shaped cells and many glial fibrils. Endothelial proliferation of tumour blood vessels was observed (Fig. 7).

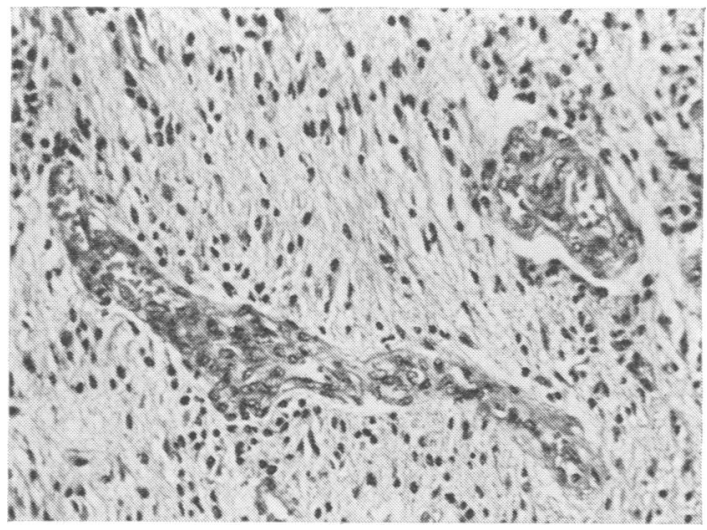

FIG. 7 Case 1. In the pons the tumour is moderately cellular, composed of fairly well-differentiated 'piloid' astrocytes.

Some endothelial proliferation of blood vessels is noted. $H$ and $E, \times 120$. 


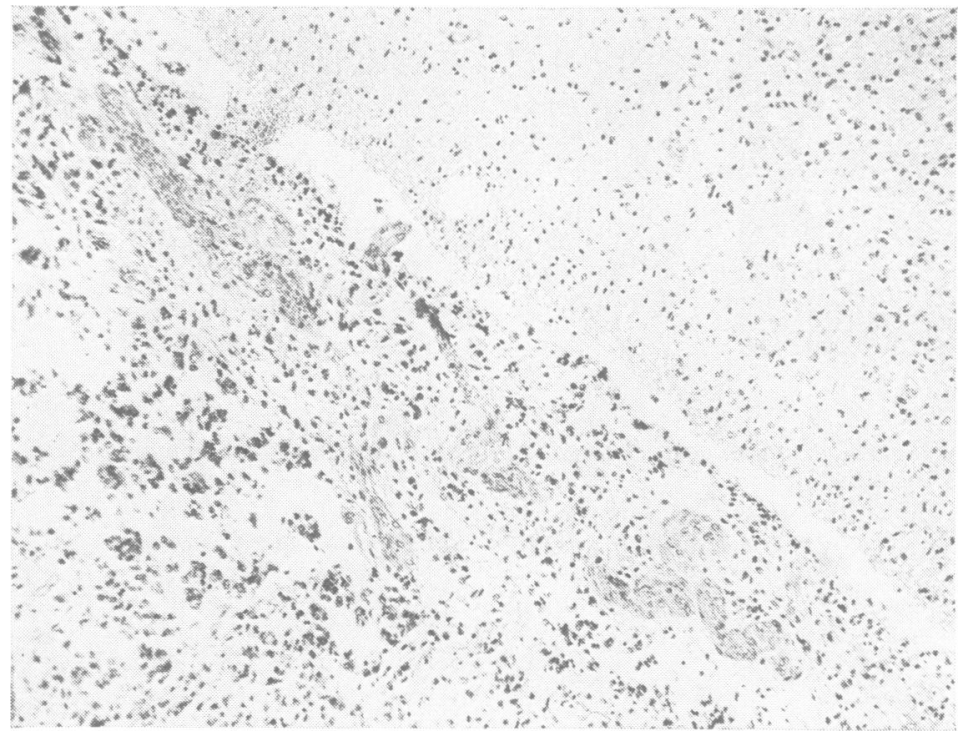

FIG. 8 Case1.Parapontine meninges: neoplastic infiltrates of the pia-arachnoid membrane appear more cellular than in the pons itself. $H$ and $E, \times 80$.

There were also areas of higher cell density, haemorrhages, and necroses. The peripontine meninges that were invaded by the tumour showed markedly increased cellularity compared with the intrapontine neoplasm (Fig. 8), whereas the spinal subarachnoid deposits and the extradural masses showed a highly cellular, anaplastic tumour composed of small dark cells with scanty cytoplasm and chromatin rich, round to carrot-shaped nuclei (Fig. 9). These por-

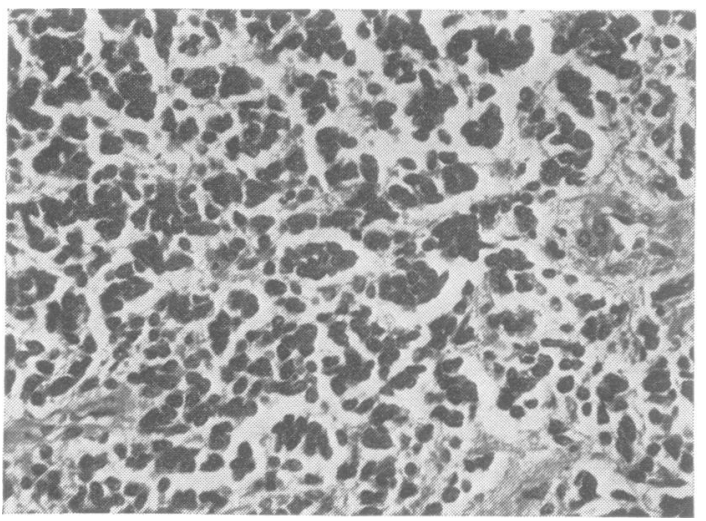

FIG. 9 Case 1. Tumour implants in the cauda equina and extradural extensions show highly cellular small cell neoplasm reminiscent of a medulloblastoma. $H$ and $E, \times 240$. tions of the tumour closely resembled a medullo产 blastoma.

CASE $2^{1}$

C.V., a 51 year old white male, was admitted to the University of Kansas Medical Center on 23 June 1963, with a six month history of intermittent numbness and tingling of the left hand, neck, shoulder, and arm, vertigo associated with movement of the head, increasing ataxia and weakness of the left arm and leg, headache, nausea, and vomitting, weight loss of $15.9 \mathrm{~kg}$, and a tendency to faint when standing. On admission, his blood pressure was $100 / 70 \mathrm{mmHg}$. The patient was chronically ill and unable to stand because of fainting. There was extreme vertigo on movement of the neck, nuchal rigidity with positive Kernig's sign, diplopia on lateral gaze bilaterally, nystagmus, and loss of vibratory sense on the left side with ataxia of the left arm and leg. Cerebrospinal fluid examination showed 2000 WBC per $\mathrm{mm}^{3}(72 \%$ polymorphonuclear leucocytes, $28 \%$ lymphocytes) sugar $1.67 \mathrm{mmol} / \mathrm{l}$ and protein $15.0 \mathrm{~g} / \mathrm{l}$. No tumour cells were identified. India ink preparation was negative. Brain scan (isotope) showed increased activity in the right parietal area. A pneumoencephalogram was

1 This case has been discussed previously as a CPC at the University of Kansas Medical Center and was published as such in the April 1968 issue of the Journal of the Kansas Medical Society. It is being included here with the permission of the Editors of that journal. 


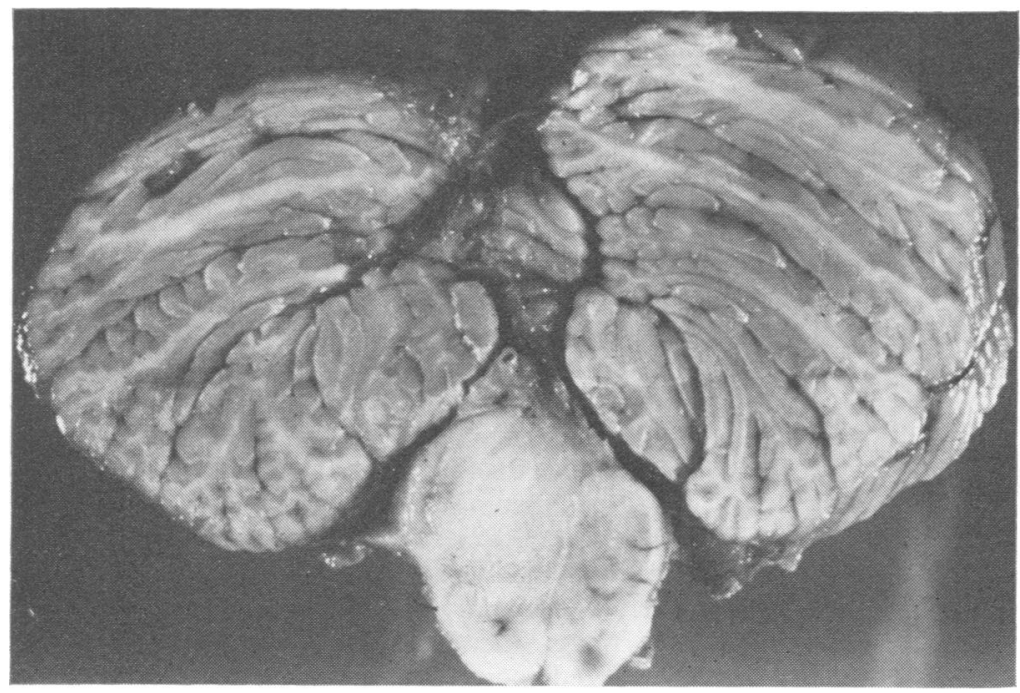

FIG. 10 Case 2. In the left upper-outer quadrant of the medulla a grey-white swelling: infiltrating astrocytoma is noted.

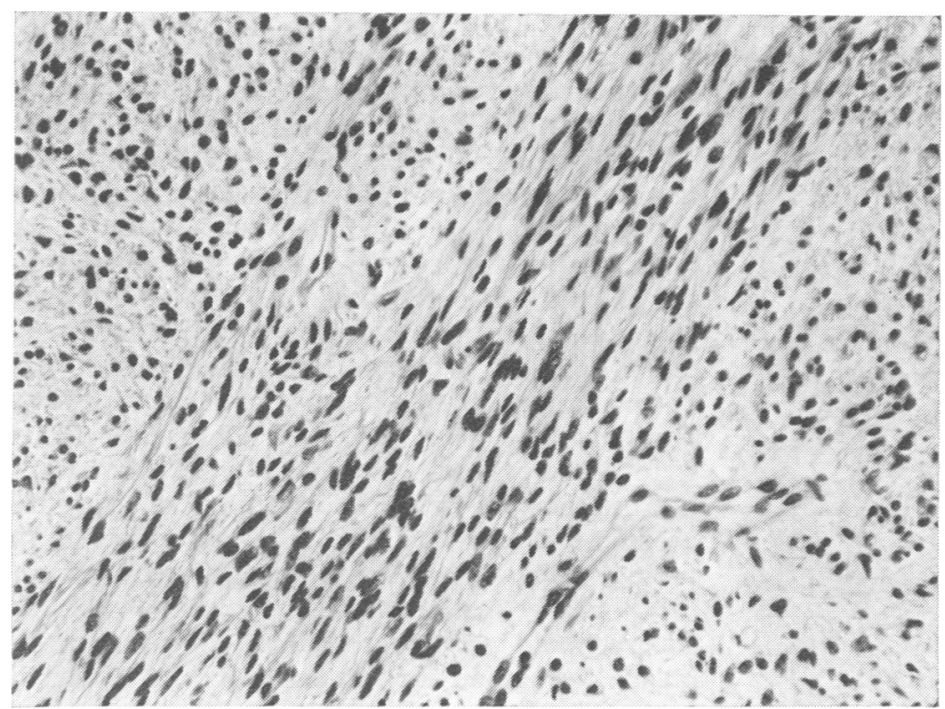

FIG. 11 Case 2. Within the medulla, bipolar neoplastic astrocytes conform to the shape and direction of fibre tracts. $H$ and $E, \times 170$. attempted unsuccessfully because of spontaneous clotting of the CSF and the patient's inability to sit in the upright position without losing consciousness. In spite of negative India ink preparations and cultures, a fungal meningitis was strongly suspected and the patient received amphotericin- $B$ by intravenous drip for 10 days until the day before death. On that day he lapsed into a semicomatose state, developed laboured respiration, and died on the following day, after 27 days of hospitalization.

PATHOLOGICAL FINDINGS The general necropsy showed pulmonary oedema and biventricular cardiac dilatation. There were erosions in the gastric mucosa and there was about $200 \mathrm{ml}$ of bloody fluid in the gastrointestinal tract. 


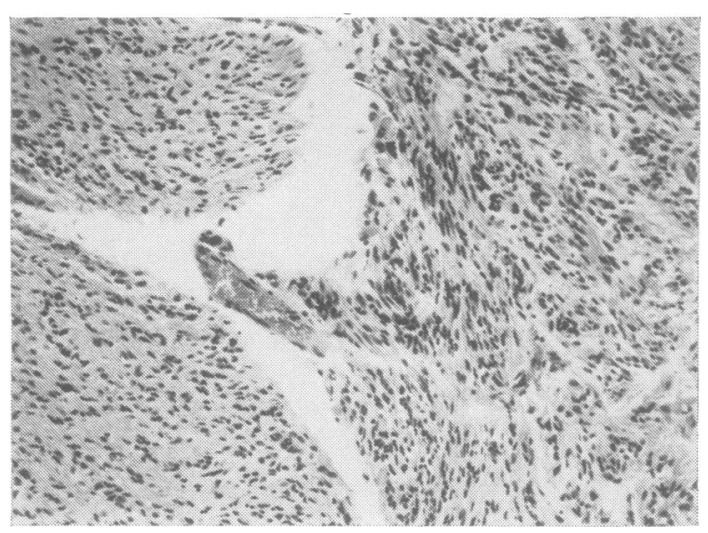

FIG. 12 Case 2. The medulla (left) contains somewhat less cellular tumour than the leptomeninges (right) that had become infiltrated by neoplastic astrocytes. $H$ and $E, \times 26$.

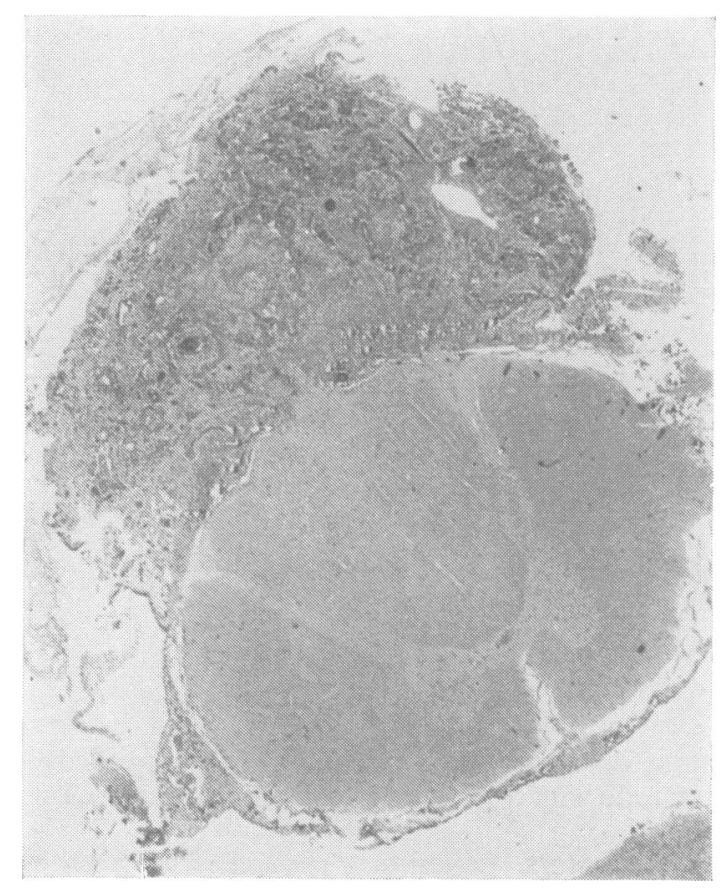

FIG. 13 Case 2. Upper thoracic spinal cord with subdural and subarachnoid tumour masses. $H$ and $E, \times 5$.
Nervous system The brain weighed $1520 \mathrm{~g}$. The $\mathbb{Q}$ cerebral hemispheres were unremarkable, and the lateral and third ventricles, basal ganglia, midbrain, pons, and cerebellum showed no abnormalities. The medulla oblongata appeared greatly swollen ${ }^{0}$ and on cross-section a greyish-white mass with indistinct borders was seen in the left upper quadrant of the medulla occupying the area of the vestibular and cuneate nuclei and the left restiform body (Fig. 10). The leptomeninges surrounding the medulla were filled with an opaque, slightly grumous, mostly gelatinous material which also surrounded the lowermost portion of the medulla, grossly obliterated the foramen magnum, and could be seen extending the full length of the spinal cord as a grey-white gelatinous meningeal sheath.

Microscopically, the tumour within the medulla was ill-defined and extended beyond its grossly observed boundaries, mostly by infiltrating through fibre tracts, in many areas sparing neurones and myelinated axons that were lying between advancing tumour cells. Most cells were elongated, bipolar $\underset{\omega}{\omega}$ astrocytes ('pilocytic variant') elaborating many glial fibrils. In the left upper quadrant of the medulla where the centre of the tumour appeared to bo located, no surviving nervous tissue was found and a greater density of neoplastic cells was encountere of $\vec{c}$ Even here, however, the majority of tumour cells were fairly well differentiated bipolar cells witb only an occasional mitosis (Fig. 11). Similar bipolak tumour cells occupied the surrounding leptomenine $\overrightarrow{0}$ ges (Fig. 12) but around the lower medulla-an particularly in the cell masses surrounding the spinal cord (Fig. 13) - anaplasia was much more pronounced with marked pleomorphism of tumour cells (Fig. 14). In these areas tumour cell sizes ranged from small almost 'lymphoid' cells to multinucleated giant cells (Fig. 15), mitotic figures were numerous and there were extensive areas of necrosis as well as some collections of acute and chronic inflammatory cells. It was obvious that the tumour became much more dedifferentiated and histologically malignant while growing within the subarachnoid space, compared with the mostly bland 'low grade' appearance within the medulla itself. (This feature of increased anaplasia, displayed by primary brain tumours after invasion of the subarachnoid space, had been repeatedly observed by us and other authors.)

\section{CASE 3}

A.H. was a 32 year old white male with a six month progressive history of right-sided tenderness, hearing loss, numbness of the right arm and face, including the right half of the tongue, and associated with weakness of the right arm and leg. The patient 


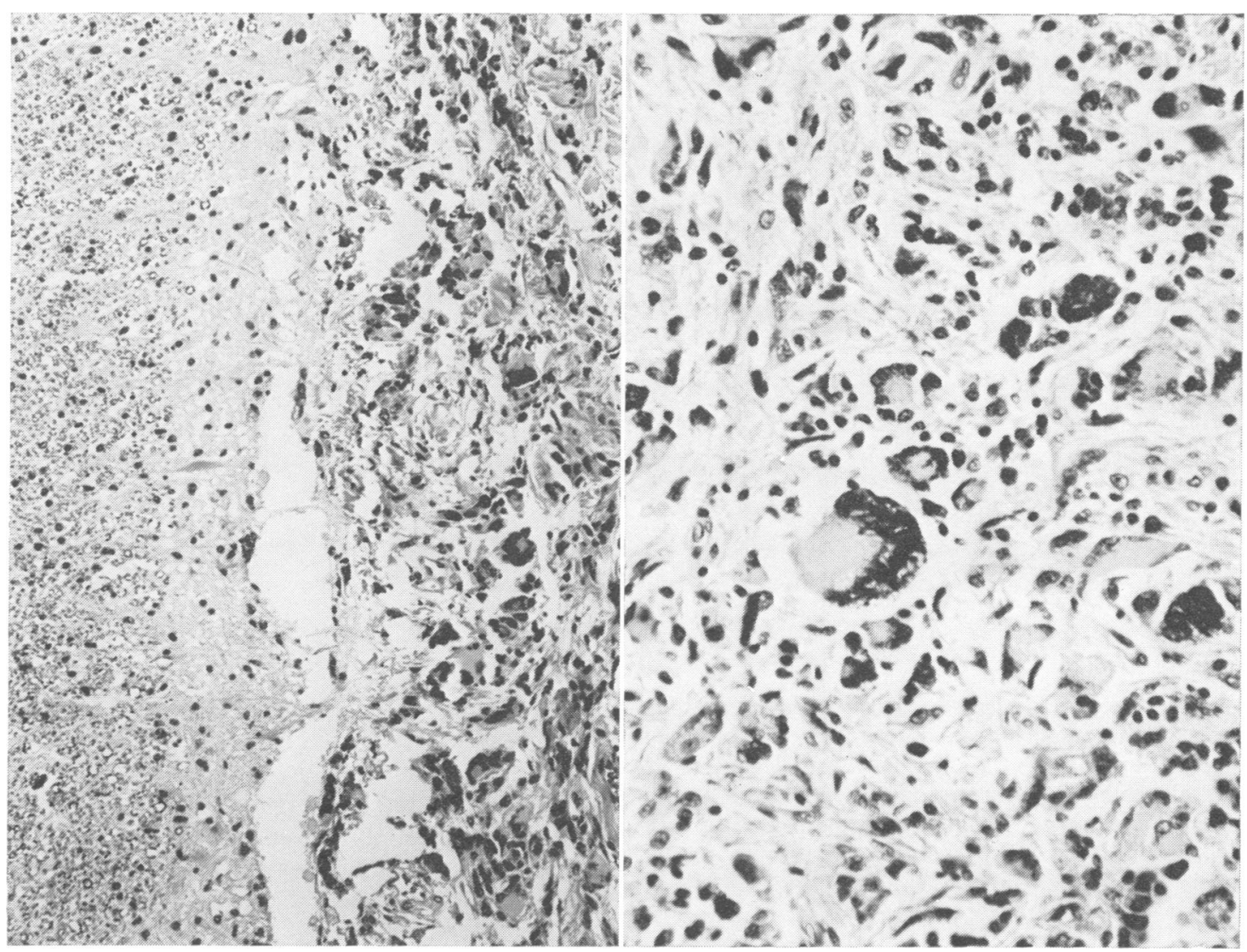

FIG. 14 (left) Case 2. Highly cellular, anaplastic tumour fills the subarachnoid meshwork (spinal cord, left, meninges right). $H$ and $E, \times 120$. FIG. 15 (right) Same area, higher power, shows great variability of tumour cells and the presence of multinucleated giant cells, characteristic of glioblastoma multiforme. $H$ and $E, \times 300$.

developed ataxia, nausea, vomiting, and diplopia. A pneumoencephalogram in March 1973 showed asymmetrical enlargement of the brain-stem consistent with a brain-stem mass (Fig. 16). A ventriculoperitoneal shunt was carried out because of the presence of partial obstructive hydrocephalus and he received 5300 rads of cobalt to the posterior fossa. There was improvement particularly in his cranial nerve findings and the patient remained with minimal right hemiparesis, ataxia, and hearing loss but showed clearing of the numbness. In August 1974 the patient developed numbness of the right leg followed rapidly by progressive numbness of the left leg and sacral area. Examination showed mild paraparesis, right greater than left, ataxic gait, positive Romberg sign with falling to the right, a right medial rectus paresis, and decreased hearing on the right with the remainder of the cranial nerves intact. Pinprick, light touch, and vibratory sense were reduced below $\mathrm{L} 1$ dermatome including the sacral segments. A myelogram showed the presence of an intradural mass causing subtotal block at T11 vertebral level. An additional intradural mass measuring $8 \times 8 \mathrm{~mm}$ was present at the level of S1 vertebra. Brain scan (isotope) was normal. CSF showed a class III cytology indicative of tumour cells. Laminectomy was carried out at T11 and $S 1$ vertebrae. At $T 11$ vertebral level a gelatinous, reddish, purple intramedullary tumour was found in the dorsal columns of the cord. This was removed by microsurgical dissection. At S1 vertebral level a mass of tumour was found filling the intradural space intimately associated with all of the local nerve roots from which it could 


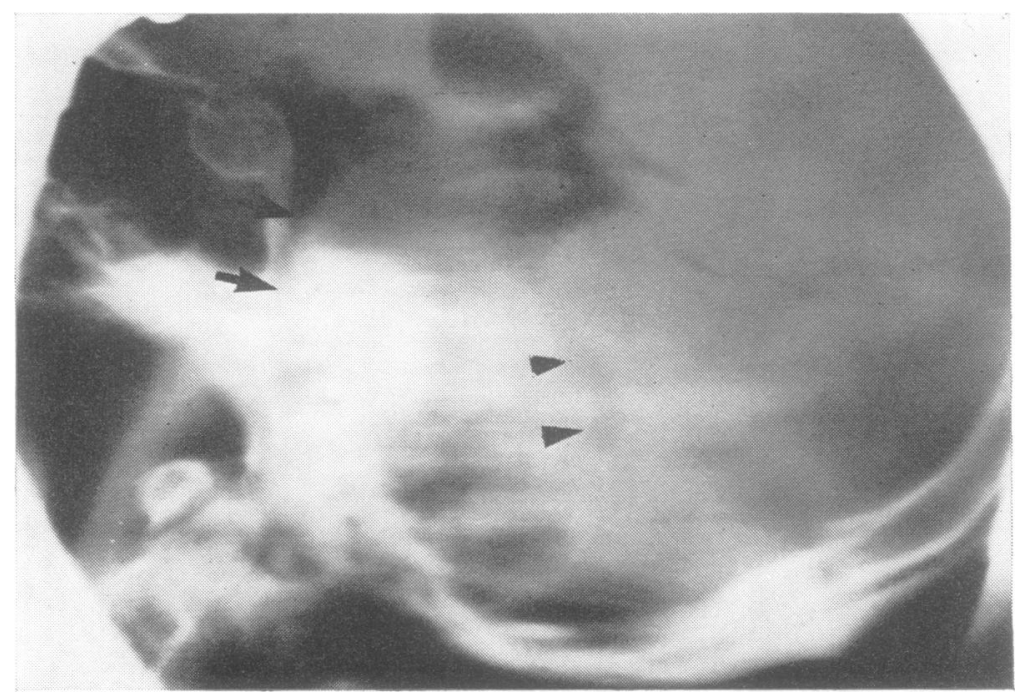

FIG. 16 Case 3. Pneumoencephalogram: Lateral radiograph showing obliteration of the prepontine cistern (arrows) and posterior displacement of the fourth ventricle (arrowheads) consistent with a mass in the brain-stem. Vertebral angiography revealed the mass to be avascular.

not be readily dissected. The biopsy specimen showed an anaplastic small cell tumour that had invaded epidural fat tissue. In a small sample of tumour cells the morphological characteristics of neoplastic astrocytes could be recognized (Fig. 17). The patient is currently receiving radiation treatment to his neural axis.

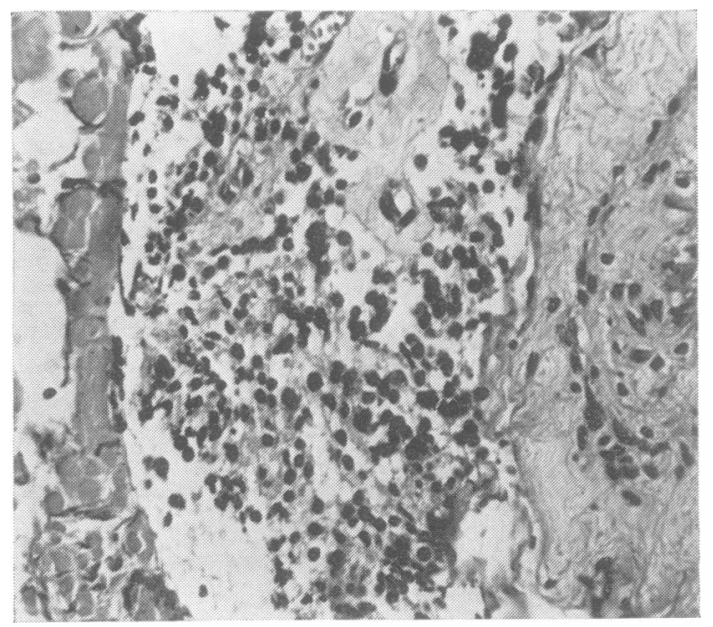

FIG. 17 Case 3. From the S1 laminectomy. Poorly differentiated astrocytes invade subdural and subarachnoid tissue spaces (The dura mater itself had been invaded.). $H$ and $E, \times 230$.

\section{DISCUSSION}

As pointed out in the introduction, spinat meningeal seeding is apparently a very rare complication of brain-stem gliomas. In the largest series of brain-stem gliomas in the literature (101 cases collected by Henschep (1955), 44 adult cases reported by White (1963), 48 cases seen at Columbia University over a period of 24 years and analysed by Bray et al. (1958), brain-stem gliomas in 40 children and adolescents reviewed by Panitch and Berg (1970), Lassman and Arjona's 27 cases (1967), Buckley's 25 cases from Cushing's series (1930), and the 37 cases of Lassiter et al. (1971)) no evidence was reported of the tumour spreading to the spinal meninges or the cauda equina in these, or other series (Horrax, 1927; Alper and Yaskin, 1939; Barnett and Hyland, 1952; Cooper et al., 1952; Penman and Smith, 1954; Golden et al., 1972). Even though a number of these brain-stem gliomas were histologically characterized as 'glioblastomas' (10 of Buckley's 욱 25 cases, all eight cases of Roth and Elvidge, 1960), none of these was observed to spread to the spinal cord or meninges. This is all the more $\tilde{O}$ striking since local meningeal invasion, tumourous envelopment of the basilar artery, and extension into the cerebellopontine angle and fourth ventricle were by no means uncommon. 
It was seen in all 13 cases of Golden et al. (1972). It is possible, of course, that in some cases of the above-listed series, spinal seeding of the brain-stem gliomas went undetected because examination of the spinal canal was not included in the necropsy and, furthermore, a small degree of neoplastic seeding may well have gone clinically undetected in the absence of pertinent symptoms or signs. Direct downward extension of a medullary tumour to involve the first two cervical segments of the spinal cord, however, was observed in one of seven cases reported by Hare and Wolf (1934) and in cases 2 and 5 of gliomas of the medulla oblongata observed by Cooper et al. (1952).

Only one of Polmeteer and Kernohan's 42 gliomas that spread to the spinal canal was of brain-stem origin: a fibrillary astrocytoma of the midbrain (Polmeteer and Kernohan, 1947). In White's series of 44 adult brain-stem gliomas (White, 1963), six patients were listed as having had 'sphincter difficulties' but the author did not elaborate on the possible cause and no anatomical or radiological evidence was presented to suggest actual metastases to the lower spinal areas. The fact that we were nevertheless able to gather three cases of this nature suggests that this is a possible complication of brain-stem tumours and would direct our attention both diagnostically and possibly in terms of radiation therapy to the spinal axis in patients with brain-stem gliomas. It is not clear why brain-stem gliomas that have already locally infiltrated the meninges and/or the fourth ventricle do not metastasize to the spinal cord more often. Dedifferentiation of the tumour within the brain-stem itself is probably not the most important factor, since in our case 2 the intramedullary portion of the tumour was quite well differentiated and many cases of pontine tumours labeled as glioblastomas in the literature (Buckley, 1930; Roth and Elvidge, 1960) failed nevertheless to spread via the spinal route, or at least such spread was not documented. It is true, however, that all of our three cases showed very marked anaplasia of the intrameningeal portion of the tumour, in case 2 showing features of giant cell glioblastoma, in case 1 that of a medulloblastoma. Dedifferentiation of a pontine astrocytoma to medulloblastoma-like tumour (although without spinal metastases) was first documented by Rubinstein et al. (1974). The penetration of the spinal dura mater and the establishment of extradural metastases in our cases 1 and 3 is also suggestive of increased malignant potential in these tumours.

In summary, our three cases of brain-stem glioma (two adults and one child) that have extensively metastasized to the spinal canal indicate that, although apparently quite rare, this pattern of metastatic spread does occur in primary gliomas of the pons and medulla.

The authors want to thank Dr Lester Lansky, Pediatric Neurologist, KUMC, for advising us about the clinical course of case 1 .

\section{REFERENCES}

Alpers, B. J., and Yaskin, J. C. (1939). Gliomas of the pons: clinical and pathologic characteristics. Archives of Neurology and Psychiatry, 41, 435-459.

Barnett, H. J., and Hyland, H. H. (1952). Tumours involving the brain stem. Quarterly Journal of Medicine, 21, 265-284.

Bray, P. F., Carter, S., and Taveras, J. M. (1958). Brain stem tumors in children. Neurology (Minneap.), 8, 1-7.

Buckley, R. C. (1930). Pontile gliomas: a pathologic study and classification of twenty-five cases. Archives of Pathology (Chic.), 9, 779-819.

Cairns, H., and Russell, D. S. (1931). Intracranial and spinal metastases in gliomas of the brain. Brain, 54, 377-420.

Cooper, I. S., Kernohan, J. W., and Craig, W. McK. (1952). Tumors of the medulla oblongata. Archives of Neurology and Psychiatry, 67, 269-282.

Golden, G. S., Ghatak, N. R., Hirano, A., and French, J. H. (1972). Malignant glioma of the brain stem, a clinicopathological analysis of 13 cases. Journal of Neuro$\log y$, Neurosurgery, and Psychiatry, 35, 732-738.

Hare, C. C., and Wolf, A. (1934). Intramedullary tumors of the brain stem. Archives of Neurology and Psychiatry, 32, 1230-1252.

Henschen, F. (1955) Tumoren des Zentralnervensystems und seiner Hüllen. In Handbuch der Speziellen Pathologischen Anatomie und Histologie, pp. 534-537, vol. 13/3. Edited by F. Henke, O. Lubarsch, and R. Rössle. Springer: Berlin.

Horrax, G. (1927) Differential diagnosis of tumours primarily pineal and primarily pontine. Archives of Neurology and Psychiatry, 17, 179-192.

Lassiter, K. R. L., Alexander, E., Davis, C. H., and Kelly, D. L. (1971). Surgical treatment of brain stem gliomas. Journal of Neurosurgery, 34, 719-725.

Lassman, L. P., and Arjona, V. E. (1967) Pontine gliomas of childhood. Lancet, 1, 913-915.

Panitch, H. S., and Berg, B. O. (1970). Brain stem tumors in childhood and adolescence. American Journal of Diseases of Children, 119, 465-472.

Penman, J., and Smith, M. C. (1954) Intracranial Gliomata. Some Clinical, Radiological and Therapeutic Aspects of 298 Cases. Medical Research Council of Great Britain Special Report No. 284, p. 70. 
Polmeteer, F. E., and Kernohan, J. W. (1947). Meningeal gliomatosis. A study of forty-two cases. Archives of Neurology and Psychiatry, 57, 593-616.

Roth, J. G., and Elvidge, A. R. (1960). Glioblastoma multiforme: A clinical survey. Journal of Neurosurgery, 17, 736-750.

Rubinstein, L. J., Herman, M. M., and Hanbery, J. W. (1974). The relationship between differentiating medulloblastoma and dedifferentiating cerebellar astrocytoma.
Light, electron microscopic, tissue, and organ culture observations. Cancer, 33, 675-690.

Russell, D. S., and Cairns, H. (1930). Spinal metastases in a case of cerebral gliomas of the type known as astrocytoma fibrillare. Journal of Pathology and Bacteriology, 33, co 383-391.

White, H. H. (1963). Brain stem tumors occurring in adults. Neurology (Minneap.), 13, 292-300. 